\title{
Vibroarthrographic analysis of patellofemoral joint arthrokinematics during squats with increasing external loads
}

\author{
Ewelina Ołowiana ${ }^{1}$, Noelle Selkow², Kevin Laudner ${ }^{3}$, Daniel Puciato ${ }^{1}$ and Dawid Bączkowicz ${ }^{*}$ (D)
}

\begin{abstract}
Background: The patellofemoral joint (PFJ) provides extremely low kinetic friction, which results in optimal arthrokinematic motion quality. Previous research showed that these friction-reducing properties may be diminished due to the increase in articular contact forces. However, this phenomenon has not been analyzed in vivo during functional daily-living activities. The aim of this study was the vibroarthrographic assessment of changes in PFJ arthrokinematics during squats with variated loads.

Methods: 114 knees from 57 asymptomatic subjects (23 females and 34 males) whose ages ranged from 19 to 26 years were enrolled in this study. Participants were asked to perform 3 trials: 4 repetitions of bodyweight squats (L0), 4 repetitions of $10 \mathrm{~kg}$ barbell back loaded squats (L10), 4 repetitions of $20 \mathrm{~kg}$ barbell back loaded squats (L20). During the unloaded and loaded (L10, L20) squats, vibroarthrographic signals were collected using an accelerometer placed on the patella and were described by the following parameters: variation of mean square (VMS), mean range (R4), and power spectral density for frequency of $50-250 \mathrm{~Hz}$ (P1) and 250-450 Hz (P2).

Results: Obtained results showed that the lowest values were noted in the unloaded condition and that the increased applied loads had a significant concomitant increase in all the aforementioned parameters bilaterally $(p<0.05)$.

Conclusion: This phenomenon indicates that the application of increasing knee loads during squats corresponds to higher intensity of vibroacoustic emission, which might be related to higher contact stress and kinetic friction as well as diminished arthrokinematic motion quality.
\end{abstract}

Keywords: Knee joint, Squat, Friction, Crepitus, Contact stress, Biomechanics

\section{Background}

The knee is one of the most loaded joints within the human organism which results in its considerable susceptibility to injuries and an increased risk of early degeneration of the articular surface $[1,2]$. The patellofemoral joint (PFJ) plays a key role in the knee extensor mechanism since the patella,

\footnotetext{
* Correspondence: baczkowicz.dawid@gmail.com

${ }^{1}$ Faculty of Physical Education and Physiotherapy, Opole University of Technology, Prószkowska 76, PL-45-578 Opole, Poland

Full list of author information is available at the end of the article
}

being the largest sesamoid bone, increases the length of the lever arm of the patellar tendon, which improves the quadriceps strength by $30-50 \%$ [3]. Additionally, the patella acts as a bony shield for the anterior trochlea and due to its interposed position in the extensor apparatus, protects against excessive friction between the quadriceps tendon and the femoral condyles [4]. An indication that the PFJ adapts to considerable loading is the thickness of the hyaline cartilage. It may reach 6-7 mm thick at the central part

(c) The Author(s). 2020 Open Access This article is licensed under a Creative Commons Attribution 4.0 International License, which permits use, sharing, adaptation, distribution and reproduction in any medium or format, as long as you give appropriate credit to the original author(s) and the source, provide a link to the Creative Commons licence, and indicate if changes were made. The images or other third party material in this article are included in the article's Creative Commons licence, unless indicated otherwise in a credit line to the material. If material is not included in the article's Creative Commons licence and your intended use is not permitted by statutory regulation or exceeds the permitted use, you will need to obtain permission directly from the copyright holder. To view a copy of this licence, visit http://creativecommons.org/licenses/by/4.0/ The Creative Commons Public Domain Dedication waiver (http://creativecommons.org/publicdomain/zero/1.0/) applies to the data made available in this article, unless otherwise stated in a credit line to the data. 
of patella, which constitutes the greatest thickness among synovial joints of the human musculoskeletal system $[5,6]$.

Physiological hyaline cartilage along with synovial fluid remarkably decreases the coefficient of kinetic friction, which determines efficiency of the knee extensor apparatus and helps protect against high compressive loads [7]. Using computer models or cadaveric specimens, researchers have shown that smooth and lubricated articular surfaces provide an extremely low level of friction, which fluctuates around $0.002 \mu$ and $0.02 \mu$, depending on testing conditions $[8,9]$. Within in vivo conditions this phenomenon is clearly visible in the evaluation of joint motion quality via vibroarthrography (VAG), a method based on the analysis of micro vibrations generated during relative movement of articular surfaces [10, 11]. This research has shown that young and healthy joints provide optimal, smooth and practically vibration free arthrokinematics [12, 13]. Using VAG, it was found that the there are many confounders of friction related to the qualitative aspects of arthrokinematics, including age-related alterations and degenerative changes within synovial joint environment, which directly translate into quicker degeneration of joint surfaces $[14,15]$.

It has been previously shown that VAG possess not only high accuracy and specificity when differentiating synovial joints' deteriorations with various biomechanical and morphological origins, but also is sensitive for identifying the changes in arthrokinematics related to the level of the joint load at the end of a performed task [16-20]. From an arthrology perspective, this finding seems to be particularly important, because the load on articular surfaces is one of the most essential factors affecting the level of kinetic friction and joint wear [7, 21]. Meanwhile, most of the previously presented research associated with analysis of load impact on articular friction and contact stress has been based on mathematical modelling or ex vivo analysis, which constitutes a considerable limitation in their clinical application [22-28]. Thus, it seems that a noninvasive method, such as vibroarthrography, might provide a new perspective on PFJ arthrokinematics analyzed in vivo. Furthermore, as it was previously postulated, the subsequent VAG analyses should consider the influence of the load level on knee arthrokinematics during functional closed kinetic chain activities [19]. In comparison to analyses of open chain activities, the closed kinetic chain provides a better reproduction of the character of the PFJ in daily activities $[23,29,30]$.

Hence, the objective of this study was to use vibroarthrographically assess the impact of load on PFJ arthrokinematics, analyzed in vivo during the squat motion. It was hypothesized that the level of vibroacoustic emission would be considerably higher during squats with increasing loads when compared to unloaded squats. We assume that the above-mentioned load-associated increase of vibroacoustic emission might be largely driven by the increase of kinetic friction and contact stress within the PFJ. The results of this study might aid clinicians' understanding of the relationship between the level of articular surfaces compressive loads and qualitative aspects of arthrokinematics considered as friction-reducing properties of diarthrosis. Furthermore, these results could broaden knowledge related to the joint biotribology, and might benefit clinicians, because the squat has long been a basic element of strength training among athletes, as well as is various rehabilitative protocols [31-34]. Because PFJ disorders are commonly encountered in sports and rehabilitation, better recognition of biomechanical behavior of the PFJ during loaded and unloaded movements is essential in order to treat it effectively [4].

\section{Methods \\ Participants}

A convenience sample of asymptomatic volunteers was recruited from students of the Faculty of Physical Education and Physiotherapy of Opole University of Technology, Poland. To be included in this study, the participants were expected to be able to easily perform a series of squats with external loads of $10 \mathrm{~kg}$ and $20 \mathrm{~kg}$. The external load of $10 \mathrm{~kg}$ constituted approximately $13 \%$ of body weight (BW) for men and $18 \%$ for women, whereas the percentage values for men and women doubled respectively for the external load of $20 \mathrm{~kg}$. Additionally, the inclusion criteria included only participants with moderate physical activity level, according to the International Physical Activity Questionnaire (long form) $[35,36]$. Moreover, only individuals with no history of knee disorder or other diagnosed injury or pathology within the lower extremity were included in the study group. The clinical evaluation of the analyzed group was based on both anamnesis (participant's self-reported medical history) and physical examination performed by a senior physiotherapist, but without radiological exclusion of the cartilage pathologies. Finally, 114 healthy knee joints from 57 volunteers (23 females and 34 males) aged 19 to 26 years were enrolled in the study. Age, gender and anthropometric data in the analyzed volunteers are given in Table 1.

\section{Assessment of arthrokinematic motion quality}

Based on previous studies, assessment of the PFJ arthrokinematic motion quality was performed with an accelerometer sensor placed $1 \mathrm{~cm}$ above the apex of the patella $[11,20,37]$.

This measurement was performed during both unloaded and loaded squat movements. In total, participants were asked to perform 3 trials: (i) 4 repetitions of bodyweight squats (L0); (ii) 4 repetitions of $10 \mathrm{~kg}$ barbell back loaded squats (L10); (iii) 4 repetitions of $20 \mathrm{~kg}$ 
Table 1 Subject demographics (mean \pm standard deviation)

\begin{tabular}{llll}
\hline & All group $(n=57)$ & Men $(n=34)$ & Women $(n=23)$ \\
\hline Age (years) & $20.7 \pm 1.9$ & $20.8 \pm 2.3$ & $20.6 \pm 1.2$ \\
Height $(\mathrm{cm})$ & $174.3 \pm 11.1$ & $180.9 \pm 8.1$ & $164.4 \pm 6.8^{*}$ \\
Weight $(\mathrm{kg})$ & $68.7 \pm 13.9$ & $77.1 \pm 11.3$ & $56.0 \pm 5.3^{*}$ \\
BMl $\left(\mathrm{kg} / \mathrm{m}^{2}\right)$ & $23.6 \pm 3.0$ & $23.5 \pm 2.8$ & $20.8 \pm 1.8$ \\
\hline
\end{tabular}

$B M I$ body mass index; *, statistically significant differences between men and women, $p<0.05$

barbell back loaded squats (L20), with one-minute rest between each test. The order of the trials was randomly selected. In the unloaded trials, the squats were performed with the hands placed behind the head, while loaded trials used barbells of $10 \mathrm{~kg}$ and $20 \mathrm{~kg}$ (Fig. 1). In all these conditions, subjects were instructed to execute the squat from a neutral position (approximately $0^{\circ}$ of knee flexion) to the depth of approximately $90^{\circ}$ of knee flexion while maintaining heel contact with the floor. The constant velocities of flexion/extension movements were kept at 48 beats per minute with a metronome and the angle of the knee joint was measured using an electrogoniometer. Each squat test lasted $10 \mathrm{~s}$, during which four cycles of squats were performed. Before data collection, each subject performed the squat maneuver within the protocol guidelines. Verbal feedback regarding both the depth and duration of the movement was provided after each training squat. The trials were repeated if the requirements were not fulfilled. An average of 4 attempts were required to obtain the 3 acceptable trials.

The VAG signals were collected using an acceleration sensor, Brüel \& Kjær model 4513B-002, with a multichannel Nexus conditioning amplifier (Brüel \& Kjær Sound \& Vibration Measurement A/S, Denmark). Data were recorded at a sampling frequency of $10 \mathrm{kHz}$ and then filtered using a fourth-order zero-phase Butterworth band-pass digital filter with cutoff frequencies between $50 \mathrm{~Hz}$ and $1000 \mathrm{~Hz}$. The variability of the VAG signal in the time domain was assessed by computing the following parameters [37, 38]:

1) the mean-squared values of an obtained signal in fixed-duration segments of $5 \mathrm{~ms}$ each and then computing the variance of the values of the parameter over the entire duration of the signal (VMS) [39];

2) signal amplitude was calculated as the difference between the mean of the four most prominent peaks and the mean of the four most prominent troughs of the VAG signal (R4).

The frequency characteristics of the VAG signal were examined by a short-time Fourier transform analysis. The short-time spectra were obtained by computing the discrete Fourier transform of segments, 150 samples each,
Hanning window, and 100 samples overlap of each segment. The spectral activity was analyzed by summing spectral power of the VAG signal in two bands: 50-250 $\mathrm{Hz}(\mathrm{P} 1)$ and $250-450 \mathrm{~Hz}(\mathrm{P} 2)$ [18, 37-40].

\section{Statistical analysis}

Normality of the distribution was assessed with the Shapiro-Wilk test. Because of a skewed distribution of VMS, R4, P1, and P2 parameter values, they were analyzed using a logarithmic transformation. Statistical significance of changes between assessment conditions (load level 0,10 and $20 \mathrm{~kg}$ ) was performed with one-way analysis of variance (ANOVA) with repeated measures, and then the Tukey's honest significant difference (HSD) test for post-hoc comparisons. Differences in values of VAG parameters between left and right lower limbs were evaluated by dependent $\mathrm{t}$-test for paired samples. For examination of correlations between analyzed variables, Pearson $r$ tests were performed. The level of significance was set at $p<0.05$. Statistical analyses were performed using Statistica version 10 (TIBCO Software Inc., Palo Alto, CA).

\section{Results}

Calculated values of analyzed VAG parameters (VMS, R4, P1 and P2), expressed as median and variance values are presented in Fig. 2 and Table 2. Moreover, for an additional expression of the VAG signals characteristics, representative plots of the vibroarthrographic registered time-series, specific for each load-related condition (L0, L10 and L20) are shown in Fig. 3. The plots contain acquired signal course expressed in volts (blue solid line, left y scale) and registered position of the joint (ROM) via electrogoniometer expressed in degrees (green dotted line, right y scale).

The performed ANOVA revealed that there was a significant main effect of the applied load on values of each analyzed parameter, similar in both lower limbs. For the left limb the results were as follows: $\mathrm{F}=11.69, p<0.001$; $\mathrm{F}=15.30, p<0.001 ; \mathrm{F}=16.70, p<0.001 ; \mathrm{F}=16.64 ; p<$ 0.001 , for VMS, R4, P1 and P2, respectively, and analogously for the right limb: $\mathrm{F}=17.94, p<0.001 ; \mathrm{F}=17.75$, $p<0.001 ; \mathrm{F}=18.35 ; p<0.001 ; \mathrm{F}=19.02 . p<0.001$. Subsequently, using the post-hoc test we identified that the rising level of the applied load has a significant impact on increase of all VAG parameters, in both lower limbs (Fig. 2 and Table 2). The lowest values of VMS, R4, P1 and P2 parameters were noted during motion without additional load (L0). These values reflect the characteristics of the signals course typical for this condition, when signals possessed low amplitude and variability, only with small, occasional peaks (Fig. 3a). Application of 10 $\mathrm{kg}$ load (L10) resulted in a statistically significant increase of all parameters (Table 2). It is also seen in Fig. 


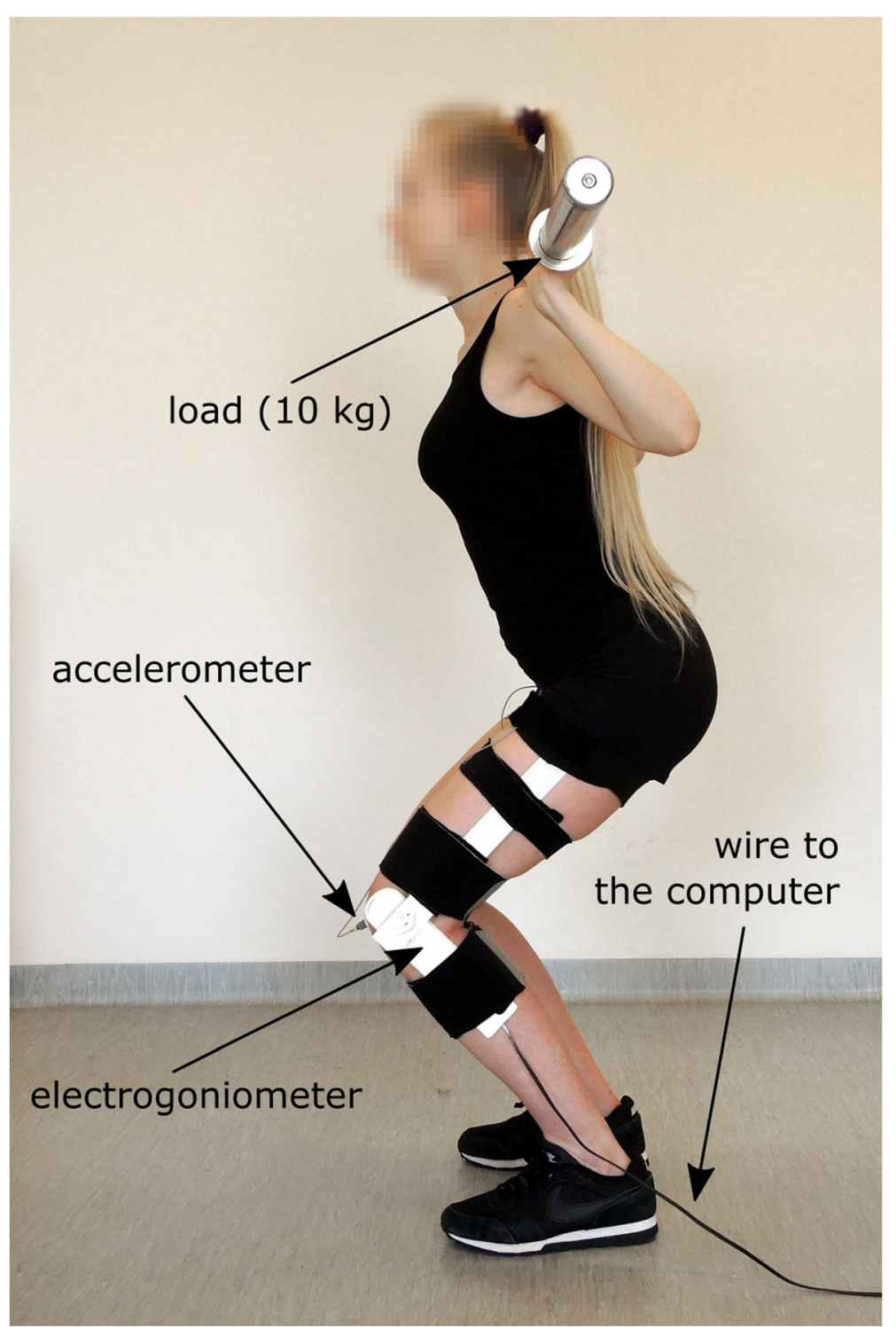

Fig. 1 Participant during assessment (10 kg load)

$3 \mathrm{~b}$ is that the motion with additional load generated signals with higher amplitude and variability, as compared to the L0 assessment. However, the highest values of VMS, R4, P1 and P2 parameters were observed in L20 condition, which were significantly higher than in the L10 condition, except comparison of the left limb VMS (Fig. 2 and Table 2). In this situation, when movements were performed under $20 \mathrm{~kg}$ load, the VAG signals possessed a more complex course with high peaks, repeatable in each cycle of motion (Fig. 3c). It should be also noted, that when compared bilaterally, there were no VAG differences, in each load condition.

In our study we also analyzed the relationships between values obtained in the left and right lower limbs (Table 3). Statistical analysis showed the presence of moderate positive correlations, especially in the P1 parameter, for which interactions were significant in all load-related conditions. Nevertheless, for VMS, R4 and P2 correlations have been also established, but only in the L10 and L20 assessments. Moreover, there were some dependencies in all VAG values when L0 was compared with L10, and L10 with L20 trials (Table 4).

\section{Discussion}

Following previous publications, our experiment assumed that the intensity of acquired vibroacoustic emission waves is closely associated with the kinetic friction and represents friction-induced vibrations generated by relative sliding and rolling of adjacent articular surfaces. From biomechanical and tribological points of view the 


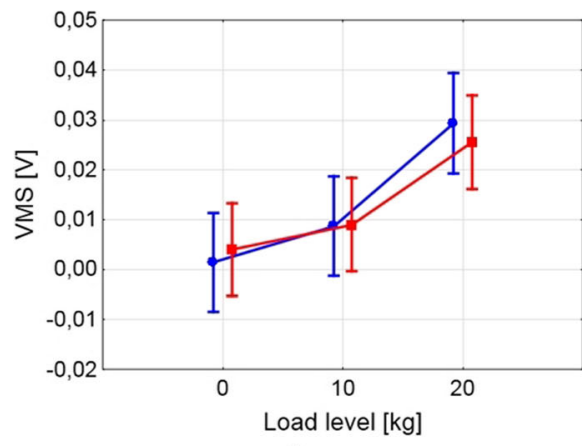

A

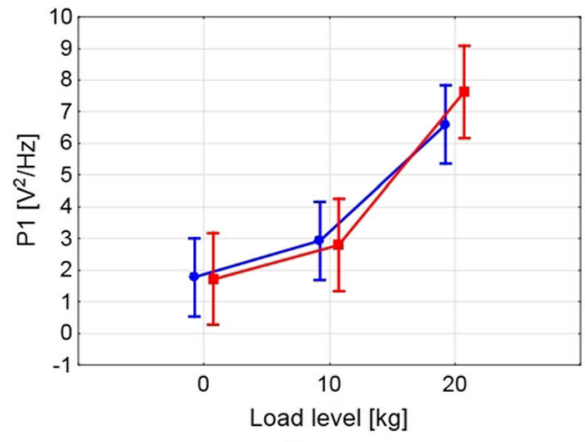

C
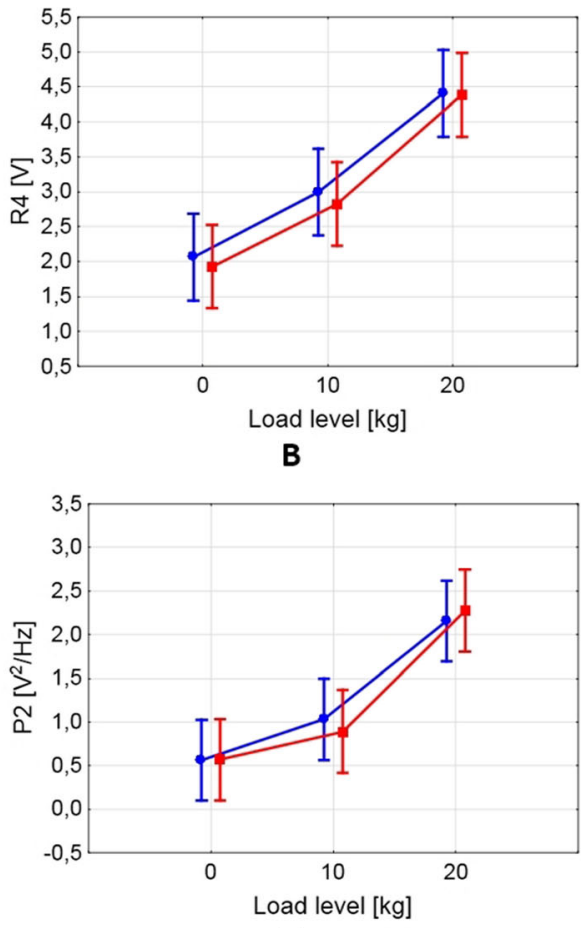

D

Fig. 2 Values of vibroarthrographic parameters in the conditions analyzed (blue round marks, left limb; red square marks, right limb)

ability of the articular surfaces to move smoothly against each other with low frictional noise indicates optimal arthrokinematic motion related with low kinetic friction, and as a result contributes to slow wear of cartilage [20]. The presented findings of this study confirm that during a knee flexion-extension movement with the load of the body weight, the PFJ arthrokinematic motion possesses low-vibration characteristics, despite relatively high values of articular surface load, typical for this analyzed condition. It has been experimentally proven via cadaveric and mathematical models that the contact forces of the PFJ articular surfaces while performing a squat may even reach $3-3.5 \mathrm{kN}$ and the peak contact pressure equals $\sim 8-9$
$\mathrm{MPa}$ at $90^{\circ}$ of knee flexion, which corresponds to multifold values of human body weight [30, 31, 41]. However, due to the friction-reducing properties of synovial joints, the coefficient of friction, which is defined as the ratio between strength required to generate gliding motility and pressure force of the body towards a particular surface, is still very low in the mentioned condition. It fluctuates around $0.03 \mu$, which is only slightly higher than coefficient of friction values typical for unloaded PFJ motion [42-44]. In our study this phenomenon is observed as relatively smooth and flat VAG signals, representing low vibroacoustic emission. Both variability (VMS) and amplitude (R4) of representative signals are characterized by

Table 2 Parameters of vibroarthrographic signals under different loads

\begin{tabular}{|c|c|c|c|c|c|c|c|c|}
\hline & \multicolumn{2}{|c|}{$\begin{array}{l}\text { VMS [V] } \\
\text { median } \pm \text { variance }\end{array}$} & \multicolumn{2}{|c|}{$\begin{array}{l}\mathrm{R} 4 \mathrm{~V}] \\
\text { median } \pm \text { variance }\end{array}$} & \multicolumn{2}{|c|}{$\begin{array}{l}\mathrm{P} 1\left[\mathrm{~V}^{2} / \mathrm{Hz}\right] \\
\text { median } \pm \text { variance }\end{array}$} & \multicolumn{2}{|c|}{$\begin{array}{l}\mathrm{P} 2\left[\mathrm{~V}^{2} / \mathrm{Hz}\right] \\
\text { median } \pm \text { variance }\end{array}$} \\
\hline & Left & Right & Left & Right & Left & Right & Left & Right \\
\hline No load (L0) & $0.001 \pm 0.004$ & $0.004 \pm 0.019$ & $2.06 \pm 1.24$ & $1.93 \pm 1.62$ & $1.77 \pm 1.51$ & $1.72 \pm 2.49$ & $0.57 \pm 0.88$ & $0.57 \pm 1.08$ \\
\hline 10 kg load (L10) & $0.009 \pm 0.021$ & $0.009 \pm 0.026$ & $3.00 \pm 1.92$ & $2.82 \pm 2.00$ & $2.92 \pm 2.62$ & $2.80 \pm 3.92$ & $1,03 \pm 1,24$ & $0.89 \pm 1.24$ \\
\hline 20 kg load (L20) & $0.029 \pm 0.060$ & $0.026 \pm 0.051$ & $4.41 \pm 3.27$ & $4.38 \pm 2.85$ & $6.60 \pm 7.37$ & $7.63 \pm 8.10$ & $2.16 \pm 2.56$ & $2.28 \pm 254$ \\
\hline \multicolumn{9}{|l|}{$p$-values } \\
\hline L0 vs L10 & 0.019 & 0.005 & 0.008 & 0.003 & 0.027 & 0.031 & 0.006 & 0.007 \\
\hline L10 vs L20 & 0.102 & 0.019 & 0.044 & 0.032 & 0.006 & 0.002 & 0.031 & 0.009 \\
\hline L0 vs L20 & $<0.001$ & $<0.001$ & $<0.001$ & $<0.001$ & $<0.001$ & $<0.001$ & $<0.001$ & $<0.001$ \\
\hline
\end{tabular}

VMS variability of the mean squares calculated in 5 ms windows; R4, mean of four maximal and four minimal values; P1, P2, power spectral density bands: 50-250 $\mathrm{Hz}$ and $250-450 \mathrm{~Hz}$, respectively; bolded values indicate statistically significant differences 


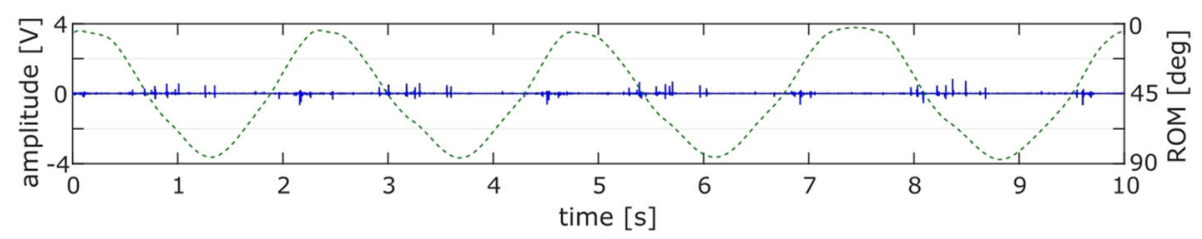

A

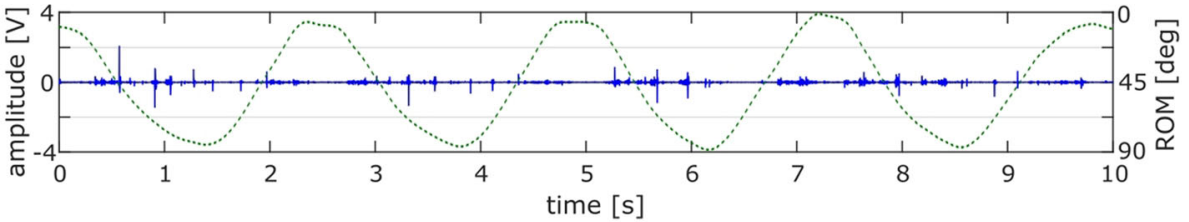

B

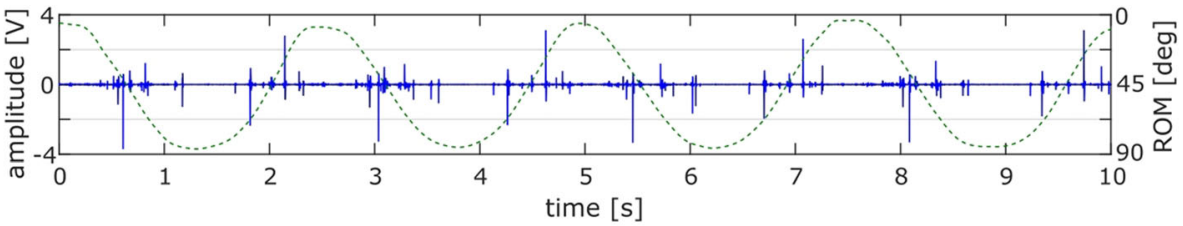

C

Fig. 3 The course of representative vibroarthrographic signals for conditions (a) with no load (b) with $10 \mathrm{~kg}$ load (c) with $20 \mathrm{~kg}$ load

low values. Especially the low values of the R4 parameter that indicate a lack of repetitive large peaks, whose presence often corresponds with macroscopic joint cartilage abnormalities or significant maltracking of articular surfaces $[18,38]$. In turn, low spectral activity analyzed by summing spectral power of the VAG signal in two bands: $50-250 \mathrm{~Hz}(\mathrm{P} 1)$ and $250-450 \mathrm{~Hz}$ (P2) seems to be related with intact integrity of the superficial layer of hyaline cartilage and an efficient lubrication mechanism [37, 45].

Nonetheless, in the present study we predominantly focused on the impact of the external load on the quality of PFJ arthrokinematic motion. As expected, the PFJ frictional noise raised near-linearly with increasing levels of external load. The application of $10 \mathrm{~kg}$ external load resulted in an average 3-fold higher variability of recorded signal (VMS) and an average $\sim 1.5$-fold increase

Table 3 Values of correlation coefficient between parameters of vibroarthrographic signals recorded for left and right lower limbs

\begin{tabular}{llllll}
\hline & & VMS & $\mathrm{R} 4$ & $\mathrm{P} 1$ & $\mathrm{P} 2$ \\
\hline No load & $\mathrm{R}$ & 0.16 & 0.13 & $\mathbf{0 . 2 8}$ & 0.14 \\
& $P$ & 0.245 & 0.349 & 0.041 & 0.297 \\
$10 \mathrm{~kg} \mathrm{load}$ & $\mathrm{R}$ & $\mathbf{0 . 4 4}$ & $\mathbf{0 . 4 7}$ & $\mathbf{0 . 4 2}$ & $\mathbf{0 . 3 1}$ \\
& $P$ & 0.001 & 0.000 & 0.002 & 0.022 \\
$20 \mathrm{~kg}$ load & $\mathrm{R}$ & $\mathbf{0 . 3 5}$ & $\mathbf{0 . 2 9}$ & $\mathbf{0 . 4 1}$ & $\mathbf{0 . 3 6}$ \\
& $P$ & 0.011 & 0.032 & 0.002 & 0.008 \\
\hline
\end{tabular}

$\mathrm{R}$, Spearman's rank correlation coefficient; $p$, value of statistical significance; VMS, variability of the mean squares calculated in 5 ms windows; R4, mean of four maximal and four minimal values; $\mathrm{P} 1, \mathrm{P} 2$, power spectral density bands: $50-250 \mathrm{~Hz}$ and $250-450 \mathrm{~Hz}$; bolded values indicate statistically significant differences of amplitude and spectral activity (R4, P1 and P2). Furthermore, the squats performed with the $20 \mathrm{~kg}$ load were characterized by further, analogous increase of the VAG signal variability/amplitude and higher, 2.5 -fold increase of spectral power in band $50-450 \mathrm{~Hz}$, when compared with the $10 \mathrm{~kg}$ load. Similar results have been presented by Andersen et al. [19], who also found divergences between different loads for all VAG parameters. However, this previous study was based on an open kinetic chain analysis and the applied loads (up to $5 \mathrm{~kg}$ ) were lower than the loads analyzed in the current study, which are more typical for different activities of daily living and sports. Moreover, although the absolute values between studies differed as a result of disparate parameters' settings being used, similar tendencies have been observed.

Research has previously reported that squatting with an external load results in significantly greater

Table 4 Values of correlation coefficient between parameters of vibroarthrographic signals in different load-related conditions

\begin{tabular}{llllll}
\hline & & VMS & $R 4$ & $P 1$ & $P 2$ \\
\hline No load \&10 kg & $R$ & $\mathbf{0 . 2 9}$ & $\mathbf{0 . 3 2}$ & $\mathbf{0 . 2 6}$ & $\mathbf{0 . 3 1}$ \\
& $P$ & 0.004 & 0.001 & 0.007 & 0.001 \\
$10 \mathrm{~kg} \& 20 \mathrm{~kg}$ & $\mathrm{R}$ & $\mathbf{0 . 2 4}$ & $\mathbf{0 . 2 9}$ & $\mathbf{0 . 3 0}$ & $\mathbf{0 . 3 0}$ \\
& $P$ & 0.014 & 0.003 & 0.003 & 0.003 \\
No load \& 20 kg & $\mathrm{R}$ & 0.07 & 0.05 & 0.02 & 0.04 \\
& $P$ & 0.477 & 0.625 & 0.879 & 0.659
\end{tabular}

$\mathrm{R}$, Spearman's rank correlation coefficient; $p$, value of statistical significance level; VMS, variability of the mean squares calculated in $5 \mathrm{~ms}$ windows; R4, mean of four maximal and four minimal values; $\mathrm{P} 1, \mathrm{P} 2$, power spectral density bands: $50-250 \mathrm{~Hz}$ and $250-450 \mathrm{~Hz}$. 'Bolded values indicate $\mathrm{p}<0.05$; bolded values indicate statistically significant differences 
patellofemoral joint reaction force and stress compared to an unloaded squat, and that the increase is proportional to the applied load [41]. Authors showed that a squat performed under a $35 \%$ of body weight external load yielded a 44\% increase in PFJ stress across all knee flexion angles, with a peak patellofemoral contact stress of $13.06 \mathrm{MPa}$ at $90^{\circ}$ of the knee flexion, whereas when unloaded, the peak patellofemoral joint contact stress equaled 9.06 MPa. Such elevated values of contact stress might cause very high frictional shear stress during gliding motion of the patella, which consequently dramatically increases kinetic friction and related frictional noise [44]. It should be also noted that the observed increase of VAG signal parameters might be the result of load-related decline in lubrication efficiency. Although many different lubrication mechanisms have been proposed, it is becoming increasingly accepted that mainly a fluid film lubrication is responsible for the low friction in synovial joints, especially at high loads $[46,47]$. Fluid film lubrication involves a thin synovia film that provides separation of the joint surfaces. Synovia being squeezed out of cartilage into the joint space as loading increases creates a thicker layer of film. Therefore, a decreased coefficient of friction with increased contact stress has been reported in many studies [48]. This observation may explain why the results reported by Ladly et al. [49] indicated that a 3 pound (1.4 $\mathrm{kg}$ ) external loading of the patellofemoral joint has an insignificant effect on VAG signal power. Nonetheless, it is generally accepted that when the contact stress reaches a medium level (4-8 MPa), the velocity of fluid exuded from the cartilage reaches its limit and there is a concomitant increase in the coefficient of friction (frictional noise) thereby, increasing contact stresses [44].

Since all participants used in this study were subjected to the same level of load, we were also able to assess intra-group relationships between the changes in characteristics of VAG signal courses under the influence of applied load and the anthropological data of the analyzed cohort. We expected some dependencies, especially between the body weight and the VAG signal values, because contact stress (considered as the main determinant of observed changes) is a parameter that reflects distribution of load and strongly depends on the area of contact between articular surfaces. However, there were no statistically significant correlation between body weight and values of VAG signal parameters. Nevertheless, weak but statistically significant correlations were noted for all the considered parameters for trials L0 and L10 as well as trials L10 and L20. This shows that subjects who had a low level of vibroacoustic emission during the bodyweight squats also obtained a low level during the loaded conditions. Thereafter, we discovered weak and moderate positive dependencies in values of all VAG parameters between the left and right lower limbs, but only for the loaded trials. Hence, there is an assumption that occurrence of the mentioned dependencies might indicate the presence of ontogenetic conditionings, associated with the friction-reducing properties of synovial joint environment and different levels of load tolerance. It is, however, a complex phenomenon that requires further extensive research.

In the light of findings reported in the current investigation, there are several limitations that should be noted. Consideration should be given that the conducted analyses were limited to asymptomatic young and agile subjects, who were performed squats with different relative external loads. So, although the present study provides crucial insights into the PFJ function during squatting with and without loads, caution should be exercised in extrapolating these data to older patient populations or those suffering from anterior knee pain syndrome. Moreover, the inclusion/exclusion criteria were based on a medical interview, but not confirmed by advanced imaging procedures. Therefore, we cannot exclude that knees of some subjects revealed minor asymptomatic cartilage changes which could have affected our results. Another potential limitation is the fact that the VAG is a method of indirect arthrokinematic analysis focused on acquisition of the vibroacoustic signal using single skinmounted accelerometer. Therefore, it should be clearly emphasized that the presented method allows for observation of only the effect of the kinetic friction phenomenon in the form of frictional noise which holds a multicomponent character. Moreover, it should be considered, that the accelerometer (despite the application of optimal localization) might detect the vibrations not only from the PFJ but also from tibiofemoral joint or other tissues [50]. However, the mechanical properties of synovial joints related to the friction and wear cannot be directly measured in vivo. Thus, it is generally accepted that the VAG method, despite some limitations, might provide sufficient, clinically meaningful information about the function and biotribological changes in whole articular environment.

Accordingly, the presented results are clinically applicable, because weight-bearing exercises, such as the squat, are frequently used during rehabilitation and are specific to many activities of daily living and sport activities. The ability to understand how friction related aspects of PFJ arthrokinematics vary among weight-bearing exercises with different loads will allow clinicians and trainers to prescribe safer and more effective rehabilitation treatments for patients and athletes during training. This is a particularly significant issue because excessive joint friction has been linked to articular cartilage degradation and may contribute to premature wear and knee pathologies (e.g. chondromalacia or osteoarthritis). 


\section{Conclusions}

The study constitutes a significant insight into the behavior of knee joint under external load conditions, specific to many functional activities. The presented results have shown that the application of increasing knee loads during squats corresponds to higher intensity of vibroacoustic emission, which might be related to higher contact stress and kinetic friction. However, it should be emphasized that these results are valid for asymptomatic healthy and young subjects.

\section{Abbreviations}

PFJ: Patellofemoral joint; VAG: Vibroarthrography

\section{Acknowledgments}

We would like to thank all of the subjects who participated in the study. We express our special gratitude to Mr. Krzysztof Kręcisz for technical assistance.

\section{Authors' contributions}

EO and DB contributed to the formulation of concepts and design of the study, analysis and interpretation of the data and writing of the manuscript. $\mathrm{KL}$, NS and DP introduced substantial revisions in the manuscript which were accepted by EO and DB. All authors read and approved the manuscript and have given consent for the submission of the final article.

\section{Funding}

No funding was received for this project.

\section{Availability of data and materials}

The datasets used and/or analyzed during the current study are available from the corresponding author on reasonable request.

\section{Ethics approval and consent to participate}

The project was approved by the Opole Voivodeship Ethics Committee (ethical approval code No. 202/06.06.2013). Before testing, all subjects provided written informed consent to participate in the study and to have their results analyzed.

\section{Consent for publication}

Not applicable.

\section{Competing interests}

The authors declare that they have no competing interests.

\section{Author details}

${ }^{1}$ Faculty of Physical Education and Physiotherapy, Opole University of Technology, Prószkowska 76, PL-45-578 Opole, Poland. ${ }^{2}$ Illinois State University, School of Kinesiology and Recreation, Normal, IL, USA. ${ }^{3}$ Beth El College of Nursing and Health Sciences, University of Colorado, Colorado Springs, CO, USA.

Received: 10 April 2020 Accepted: 24 August 2020

Published online: 27 August 2020

\section{References}

1. Clark AL. Osteoarthritis: what we have been missing in the patellofemoral joint. Exerc Sport Sci Rev. 2008;36(1):30-7. https://doi.org/10.1097/jes. Ob013e31815e4217.

2. Musumeci G. Functional anatomy in knee osteoarthritis: patellofemoral joint vs. tibiofemoral joint. J Funct Morphol Kinesiol. 2017;2(1):8. https://doi.org/ 10.3390/jfmk2010008.

3. Friedman LGM, White MS, Carroll PF, Macalena JA, Arendt EA, Ellerman JM, et al. Arthroscopy correlation inthe patellofemoral joint. Sports Med Arthrosc Rev. 2017;25(4):227-36. https://doi.org/10.1097/JSA. 0000000000000171.

4. Loudon JK. Biomechanics and pathomechanics of the patellofemoral joint. Int J Sports Phys Ther. 2016;11(6):820-30.
5. Koh JL, Stewart C. Patellar instability. Orthop Clin North Am. 2015;46(1):14757. https://doi.org/10.1016/j.ocl.2014.09.011.

6. Sherman SL, Plackis AC, Nuelle CW. Patellofemoral anatomy and biomechanics. Clin Sports Med. 2014;33:389-401. https://doi.org/10.1016/j. csm.2014.03.008

7. Jay GD, Waller KA. The biology of lubricin: near frictionless joint motion. Matrix Biol. 2014;39:17-24. https://doi.org/10.1016/j.matbio.2014.08.008.

8. Daniel M. Boundary cartilage lubrication: review of current concepts. Wien Med Wochenschr. 2014;164:88-94. https://doi.org/10.1007/s10354-0130240-2.

9. Krishnan R, Kopacz M, Ateshian GA. Experimental verification of the role of interstitial fluid pressurization in cartilage lubrication. J Orthop Res. 2004;22: 565-70. https://doi.org/10.1016/j.orthres.2003.07.002.

10. Rangayyan RM, Wu YF. Screening of knee-joint vibroarthrographic signals using statistical parameters and radial basis functions. Med Biol Eng Comput. 2008;46(3):223-32. https://doi.org/10.1007/s11517-007-0278-7.

11. Bączkowicz D, Kręcisz K. Vibroarthrography in the evaluation of musculoskeletal system - a pilot study. Ortop Traumatol Rehabil. 2013;15(5): 407-16. https://doi.org/10.5604/15093492.1084242.

12. Wu Y, Chen P, Luo X, et al. Quantification of knee vibroarthrographic signal irregularity associated with patellofemoral joint cartilage pathology based on entropy and envelope amplitude measures. Comput Methods Prog Biomed. 2016;130:1-12. https://doi.org/10.1016/j.cmpb.2016.03.021.

13. Bączkowicz D, Majorczyk E, Kręcisz K. Age-related impairment of quality of joint motion in vibroarthrographic signal analysis. Biomed Res Int. 2015; 2015:591707. https://doi.org/10.1155/2015/591707.

14. Kim KS, Seo JH, Kang JU, Song CG. An enhanced algorithm for knee joint sound classification using feature extraction based on time-frequency analysis. Comput Methods Prog Biomed. 2009;94(2):198-206. https://doi.org/ 10.1016/j.cmpb.2008.12.012.

15. Yang S, Cai S, Zheng F, Wu Y, Liu K, Wu M, et al. Representation of fluctuation features in pathological knee joint vibroarthrographic signals using kernel density modeling method. Med Eng Phys. 2014;36(10):1305-11. https://doi.org/10.1016/j.medengphy.2014.07.008.

16. Tanaka N, Hoshiyama M. Vibroarthrography in patients with knee arthropathy. J Back Musculoskelet Rehabil. 2012;25(2):117-22. https://doi. org/10.3233/BMR-2012-0319.

17. Nalband S, Sundar A, Prince AA, Agarwal A. Feature selection and classification methodology for the detection of knee-joint disorders. Comput Methods Prog Biomed. 2016;127:94-104. https://doi.org/10.1016/j.cmpb.2016.01.020.

18. Kręcisz K, Bączkowicz D. Analysis and multiclass classification of pathological knee joints using vibroarthrographic signals. Comput Methods Prog Biomed. 2018;154:37-4. https://doi.org/10.1016/j.cmpb.2017.10.027.

19. Andersen RE, Arendt-Nielsen L, Madeleine P. Knee joint vibroarthrography of asymptomatic subjects during loaded flexion-extension movements. Med Biol Eng Comput. 2018;56(12):2301-12. https://doi.org/10.1007/s11517-0181856-6.

20. Bączkowicz D, Kręcisz K, Borysiuk Z. Analysis of patellofemoral arthrokinematic motion quality in open and closed kinetic chains using vibroarthrography. BMC Musculoskelet Disord. 2019;20(1):48. https://doi.org/ 10.1186/s12891-019-2429-z.

21. DeFrate LE, Kim-Wang SY, Englander ZA, McNulty AL. Osteoarthritis year in review 2018: mechanics. Osteoarthr Cartil. 2019;27(3):392-400. https://doi. org/10.1016/j.joca.2018.12.011.

22. Steinkamp LA, Dillingham MF, Markel MD, Hill JA. Kaufman KR biomechanical considerations in patellofemoral joint rehabilitation. Am J Sports Med. 1993;21(3):438-44. https://doi.org/10.1177/ 036354659302100319

23. Cohen Z, Roglic H, Grelsamer RP, Henry JH, Levine WN, Mow VC, et al. Patellofemoral stresses during open and closed kinetic chain exercises. Am J Sports Med. 2001;29(4):480-7. https://doi.org/10.1177/ 03635465010290041701.

24. Besier TF, Draper CE, Gold GE, Beaupré GS, Delp SL. Patellofemoral joint contact area increases with knee flexion and weight-bearing. J Orthop Res. 2005;23(2):345-50. https://doi.org/10.1016/j.orthres.2004.08.003.

25. Lorenz A, Rothstock S, Bobrowitsch E, Beck A, Gruhler A, Ipach I, et al. Cartilage surface characterization by frictional dissipated energy during axially loaded knee flexion —an in vitro sheep model. J Biomech. 2013;46(8): 1427-32. https://doi.org/10.1016/j.jbiomech.2013.03.009.

26. Salem GJ, Powers CM. Patellofemoral joint kinetics during squatting in collegiate women athletes. Clin Biomech (Bristol, Avon). 2001;16(5):424-30. 
27. Whyte EF, Moran K, Shortt CP, Marshall B. The influence of reduced hamstring length on patellofemoral joint stress during squatting in healthy male adults. Gait Posture. 2010;31(1):47-51. https://doi.org/10.1016/j. gaitpost.2009.08.243.

28. Walter C, Leichtle U, Lorenz A, Mittag F, Wülker N, Müller O, et al. Dissipated energy as a method to characterize the cartilage damage in large animal joints: an in vitro testing model. Med Eng Phys. 2013;35(9):1251-5. https://doi.org/10.1016/j.medengphy.2013.01.002.

29. Levin S, de Solórzano SL, Scarr G. The significance of closed kinematic chains to biological movement and dynamic stability. J Bodyw Mov Ther. 2017;21(3):664-72. https://doi.org/10.1016/j.jbmt.2017.03.012.

30. Adouni M, Shirazi-Adl A. Knee joint biomechanics in closed-kinetic-chain exercise. Comput Methods Biomech Biomed Engin. 2009;12(6):661-70. https://doi.org/10.1080/10255840902828375.

31. Escamilla RF, Zheng N, Macleod TD, Edwards WB, Hreljac A, Fleisig GS, et al. Patellofemoral joint force and stress between a short-and long-step forward lunge. J Orthop Sports Phys Ther. 2008;38(11):681-90. https://doi.org/10. 2519/jospt.2008.2694.

32. Powers CM, Ho KY, Chen YJ, Souza RB, Farrokhi S. Patellofemoral joint stress during weightbearing and non-weightbearing quadriceps exercises. J Orthop Sports Phys Ther. 2014;44(5):320-7. https://doi.org/10.2519/jospt. 2014.4936.

33. Eliassen W, Saeterbakken AH, van den Tillaar R. Comparison of bilateral and unilateral squat exercises on barbell kinematics and muscle activation. Int J Sports Phys Ther. 2018;13(5):871-81.

34. Hartmann H, Wirth K, Klusemann M. Analysis of the load on the knee joint and vertebral column with changes in squatting depth and weight load. Sports Med. 2013;43(10):993-1008. https://doi.org/10.1007/s40279-013-0073-6.

35. Winckers AN, Mackenbach JD, Compernolle S, Nicolaou M, van der Ploeg HP, Brug J, et al. Educational differences in the validity of self-reported physical activity. BMC Public Health. 2015;15:1299. https://doi.org/10.1186/ s12889-015-2656-7.

36. Jakše B, Jakše B, Pinter S, Pajek J, Mis NF. Characteristics of slovenian adults in community-based whole-food plant-based lifestyle program. J Nutr Metab. 2020;2020:6950530. https://doi.org/10.1155/2020/6950530.

37. Bączkowicz D, Majorczyk E. Joint motion quality in chondromalacia progression assessed by vibroacoustic signal analysis. PM\&R. 2016;8(11): 1065-71. https://doi.org/10.1016/j.pmrj.2016.03.012.

38. Bączkowicz D, Majorczyk E. Joint motion quality in vibroacoustic signal analysis for patients with patellofemoral joint disorders. BMC Musculoskelet Disord. 2014;15:426. https://doi.org/10.1186/1471-2474-15-426.

39. Rangayyan RM, Wu Y. Analysis of vibroarthrographic signals with features related to signal variability and radial-basis functions. Ann Biomed Eng. 2009:37:156-63. https://doi.org/10.1007/s10439-008-9601-1.

40. Bączkowicz D, Falkowski K, Majorczyk E. Assessment of relationships between joint motion quality and postural control in patients with chronic ankle joint instability. J Orthop Sport Phys Ther. 2017;47:570-7. https://doi. org/10.2519/jospt.2017.6836.

41. Wallace DA, Salem GJ, Salinas R, Powers CM. Patellofemoral joint kinetics while squatting with and without an external load. J Orthop Sports Phys Ther. 2002;32(4):141-8. https://doi.org/10.2519/jospt.2002.32.4.141.

42. Ateshian GA, Hung CT. Patellofemoral joint biomechanics and tissue engineering. Clin Orthop Relat Res. 2005:436:81-90.

43. Mabuchi K, Ujihira M, Sasada T. Influence of loading duration on the startup friction in synovial joints: measurements using a robotic system. Clin Biomech (Bristol, Avon). 1998;13(7):492-4.

44. Lizhang J, Fisher J, Jin Z. The effect of contact stress on cartilage friction, deformation and wear. Proc Inst Mech Eng H. 2011;225(5):461-75. https://doi.org/10.1177/2041303310392626.

45. Bączkowicz D, Skiba G, Szmajda M, Vařeka I, Falkowski K, Laudner K. Effects of viscosupplementation on quality of knee joint arthrokinematic motion analyzed by vibroarthrography. Cartilage. 2019;1947603519847737. https://doi.org/10.1177/1947603519847737.

46. Singh N. Synovial joints and lubrication mechanisms. Int J Comput Appl Math. 2017;12(1):23-33.

47. Mansour J. Biomechanics of cartilage. In: Oatis CA, editor. Kinesiology: The mechanics and pathomechanics of human movement, vol. 68. Bristol: Lippincott Williams and Wilkins; 2009. p. 77.

48. Katta J, Jin Z, Ingham E, Fisher J. Effect of nominal stress on the long term friction, deformation and wear of native and glycosaminoglycan deficient articular cartilage. Osteoarthr Cartil. 2009;17(5):662-8. https://doi.org/10. 1016/j.joca.2008.10.008.

49. Ladly KO, Frank CB, Bell GD, Zhang YT, Rangayyan RM. The effect of external loads and cyclic loading on normal patellofemoral joint signals. Def Sci J. 1993;43(3):201-10

50. Befrui N, Elsner J, Flesser A, Huvanandana J, Jarrousse O, Le T.N. Vibroarthrography for early detection of knee osteoarthritis using normalized frequency features. Med Biol Eng Comput 2018;56(8):1499-1514. doi:https://doi.org/10.1007/s11517-018-1785-4

\section{Publisher's Note}

Springer Nature remains neutral with regard to jurisdictional claims in published maps and institutional affiliations.
Ready to submit your research? Choose BMC and benefit from:

- fast, convenient online submission

- thorough peer review by experienced researchers in your field

- rapid publication on acceptance

- support for research data, including large and complex data types

- gold Open Access which fosters wider collaboration and increased citations

- maximum visibility for your research: over $100 \mathrm{M}$ website views per year

At BMC, research is always in progress.

Learn more biomedcentral.com/submissions 